\title{
An empirically generated responder definition for rosacea treatment
}

\author{
Gerald Staedtler' \\ Kaweh Shakery ${ }^{2}$ \\ Jan Endrikat ${ }^{3,4}$ \\ Richard Nkulikiyinka ${ }^{2}$ \\ Christoph Gerlinger ${ }^{1,4}$ \\ 'Bayer AG, Pharmaceutical Statistics, \\ ${ }^{2}$ Bayer AG, Dermatology \& Anti- \\ infectives 2, 'Bayer AG, Radiology, \\ Berlin, ${ }^{4}$ Department of Gynecology, \\ Obstetrics and Reproductive \\ Medicine, University Medical School \\ of Saarland, Homburg/Saar, Germany
}

Correspondence: Christoph Gerlinger Bayer AG, Müllerstraße 178, 13353

Berlin, Germany

Tel $+4930468 I \quad 1829$

Fax +49 3046891829

Email christoph.gerlinger@bayer.com
This article was published in the following Dove Press journal:

Clinical, Cosmetic and Investigational Dermatology

8 September 2017

Number of times this article has been viewed

Objective: The aim of this study was to empirically generate a responder definition for the treatment of papulopustular rosacea.

Methods: A total of 8 multicenter clinical studies on patients with papulopustular facial rosacea were analyzed. All patients were treated with azelaic acid and/or comparator treatments. The severity of rosacea was described by the Investigator Global Assessment (IGA) and the number of lesions. Patients with the IGA score of "clear/minimal" were considered as responders, and those staying in the range of IGA "mild to severe" as nonresponders. The respective number of lesions was determined.

Results: A total of 2,748 patients providing 12,410 measurements were included. After treatment, responders showed 2.23 \pm 2.48 lesions (median 2 lesions [0-3]), and nonresponders showed $13.74 \pm 10.40$ lesions (median 12 lesions [6-18]). The optimal cutoff point between both groups was 5.69 lesions.

Conclusion: The calculated cutoff point of 5.69 lesions allows discrimination of responders (5 or less remaining lesions) and nonresponders ( 6 or more remaining lesions) of therapeutic interventions in rosacea.

Keywords: rosacea, Investigator Global Assessment, facial lesions, responder

\section{Introduction}

Rosacea is a chronic cutaneous disorder primarily affecting the convexities of the central face. According to the National Rosacea Society Expert Committee, the presence of one or more of the following primary features (concentrated on the convex areas of the face) is indicative of rosacea: 1) flushing (transient erythema), 2) non-transient erythema, 3 ) papules and pustules, and 4) telangiectasia. ${ }^{1}$ In addition to these troublesome physical symptoms, increasing rosacea severity has been reported to correlate with greater rates of anxiety and depression and lower quality of life. ${ }^{2}$ Although the exact etiology of rosacea remains unknown, both genetic and environmental factors are believed to have an impact on the pathogenesis of this disease. ${ }^{3}$ The onset of rosacea is most frequently seen in adults between 30 and 50 years of age, often showing female predominance. ${ }^{4}$

Pharmacological treatments used for rosacea include topical drugs, oral drugs and oral/topical drug combination therapy. Not all of these treatment options have been approved for this indication. Topical treatments include active pharmaceutical ingredients such as azelaic acid, metronidazole, ivermectin, brimonidine, clindamycin, permethrin, tretinoin, sulfacetamide/sulfur and benzoyl peroxide. Systemic treatments 
include oral antibiotics such as tetracyclines, doxycycline, minocycline and azithromycin, as well as in some cases isotretinoin. ${ }^{5}$

In the past decades, a variety of clinical criteria have been used to assess symptom severity, including different techniques of erythema evaluation, different assessment scales of global disease severity and counting inflammatory lesions (i.e., papules and pustules). ${ }^{5}$ Yet, over the years, counting of inflammatory lesions remained a stable outcome measurement for the disease severity. Despite decades of studies in the field, it has never been defined how a successful therapeutic intervention would reflect in the actual lesion counts.

In this study, on the basis of data from 8 previous clinical studies, ${ }^{6-12}$ we aimed to empirically generate a lesion countbased success definition for rosacea treatment.

\section{Methods}

\section{Studies included}

We included a total of 8 multicenter clinical Phase II-IV development studies with 2,748 patients in our analysis ${ }^{6-12}$ (Table 1). All studies had a double-blind or investigator-blind design and investigated topical azelaic acid gel or foam $15 \%$ vs vehicle or active comparator over a treatment period of at least 12 weeks. In 1 case, a topical/systemic combination therapy was applied. The studies were performed between January 2001 and January 2014 in the USA. All were prospectively planned in compliance with "International Conference on Harmonization Good Clinical Practice" guidelines following the approval by applicable ethics committees/ institutional review boards. Therefore, for this meta-analysis, consultation of ethics committees/institutional review boards and written informed consent of the patients were deemed not necessary.

The objectives of these studies were to evaluate the efficacy and safety of topical azelaic acid (compared to different types of control) in patients suffering from subtype 2 rosacea (papulopustular rosacea) in different degrees of severity. Study essentials are provided in Table 1 and have been previously published.

\section{Definitions and target variable}

The investigators counted and recorded the facial inflammatory lesions (papules and pustules) at baseline and after distinct, predefined time points of therapy. In addition to counting the lesions, the investigators described their assessment of disease severity separately by using a standardized

Table I Characteristics of 8 studies for the treatment of papulopustular rosacea

\begin{tabular}{|c|c|c|c|c|c|c|c|c|}
\hline Clinical phase & II & III & III & III & IIIB & IIIB & III & IV \\
\hline Study period & $\begin{array}{l}12 / 2009- \\
8 / 2010\end{array}$ & $\begin{array}{l}|/ 200|- \\
7 / 200 \mid\end{array}$ & $\begin{array}{l}2 / 2001- \\
6 / 2001\end{array}$ & $\begin{array}{l}10 / 2001- \\
5 / 2002\end{array}$ & $\mathrm{I} / 2004-12 / 2004$ & $\begin{array}{l}12 / 2006- \\
6 / 2007\end{array}$ & $\begin{array}{l}9 / 2012- \\
1 / 2014\end{array}$ & 2/2009-7/2009 \\
\hline Study design & $\begin{array}{l}\text { Double-blind, } \\
\text { randomized }\end{array}$ & $\begin{array}{l}\text { Double-blind, } \\
\text { randomized }\end{array}$ & $\begin{array}{l}\text { Double-blind, } \\
\text { randomized }\end{array}$ & $\begin{array}{l}\text { Double-blind, } \\
\text { randomized }\end{array}$ & $\begin{array}{l}\text { I2-week open- } \\
\text { label + } 24 \text {-week } \\
\text { double-blind }\end{array}$ & $\begin{array}{l}\text { Double-blind, } \\
\text { randomized }\end{array}$ & $\begin{array}{l}\text { Double-blind, } \\
\text { randomized }\end{array}$ & $\begin{array}{l}\text { Investigator- } \\
\text { blind, } \\
\text { randomized }\end{array}$ \\
\hline Number of centers & 20 & 15 & 14 & 15 & 14 & 7 & 49 & 17 \\
\hline Treatment & $\begin{array}{l}\text { Azelaic acid } \\
\text { foam, } 15 \%\end{array}$ & $\begin{array}{l}\text { Azelaic acid } \\
\text { gel, } 15 \%\end{array}$ & $\begin{array}{l}\text { Azelaic acid } \\
\text { gel, } 15 \%\end{array}$ & $\begin{array}{l}\text { Azelaic acid } \\
\text { gel, } 15 \%\end{array}$ & $\begin{array}{l}\text { Azelaic acid } \\
\text { gel, } 15 \%+ \\
\text { doxycycline oral }\end{array}$ & $\begin{array}{l}\text { Azelaic acid } \\
\text { gel, } 15 \%\end{array}$ & $\begin{array}{l}\text { Azelaic acid } \\
\text { foam, } 15 \%\end{array}$ & $\begin{array}{l}\text { Azelaic acid gel, } \\
15 \%\end{array}$ \\
\hline Dose of treatment & $\begin{array}{l}0.5 \mathrm{~g} \text { foam, } \\
\text { BID }\end{array}$ & 0.5 g gel, BID & 0.5 g gel, BID & 0.5 g gel, BID & $\begin{array}{l}0.5 \mathrm{~g} \text { gel, BID, } \\
\text { doxycycline } \\
100 \mathrm{mg}\end{array}$ & $\begin{array}{l}0.5 \mathrm{~g} \text { gel, } \\
\text { OPD }\end{array}$ & $\begin{array}{l}0.5 \mathrm{~g} \text { foam, } \\
\text { BID }\end{array}$ & $\begin{array}{l}0.5 \mathrm{~g} \text { gel, BID } \\
+ \text { doxycycline } \\
40 \mathrm{mg}\end{array}$ \\
\hline Comparator & Vehicle & Vehicle & Vehicle & $\begin{array}{l}\text { Metronidazole } \\
\text { gel, } 0.75 \% \text {, } \\
\text { OPD }\end{array}$ & $\begin{array}{l}24 \text { weeks vs } \\
\text { vehicle }\end{array}$ & $0.5 \mathrm{~g}$ gel, BID & Vehicle & $\begin{array}{l}\text { Metronidazole } \\
\text { gel, I\% OPD } \\
\text { + doxycycline } \\
40 \text { mg OPD p.o. }\end{array}$ \\
\hline $\begin{array}{l}\text { Treatment duration } \\
\text { (weeks) }\end{array}$ & 12 & 12 & 12 & 15 & $12+24$ & 12 & 12 & 12 \\
\hline $\begin{array}{l}\mathrm{N} \text { (treatment/ } \\
\text { comparator) }\end{array}$ & $\begin{array}{l}401 \\
(198 / 204)\end{array}$ & $\begin{array}{l}329 \\
(164 / 165)\end{array}$ & $\begin{array}{l}335 \\
(169 / 166)\end{array}$ & $251(124 / 127)$ & I72; I36 (6I/65) & $92(45 / 47)$ & $\begin{array}{l}961 \\
(484 / 477)\end{array}$ & 207 (106/101) \\
\hline Mean age (years) & 48.5 & 48.6 & 47.3 & 47.5 & $46.6 ; 46.4$ & 49 & 51.5 & 49.5 \\
\hline \multicolumn{9}{|l|}{ Gender } \\
\hline Female (\%) & 74.3 & 76 & 72 & 67.7 & $75 ; 74.3$ & 69.6 & 73.0 & 65.7 \\
\hline Male (\%) & 25.7 & 24 & 28 & 32.3 & $25 ; 25.7$ & 30.1 & 27.0 & 34.3 \\
\hline Reference & 12 & 6 & 6 & 7 & 8 & 9 & 10 & II \\
\hline
\end{tabular}

Abbreviations: BID, twice a day; OPD, once per day; p.o., orally. 
"Investigator Global Assessment" (IGA) scale - a 5-point score ranging from "clear" (no symptoms) to "severe" (in older studies, the investigator was allowed to use intermediate scores "mild to moderate" and "moderate to severe"; Table 2). These end points are commonly accepted in papulopustular rosacea. A total of 4 of the studies were pivotal studies leading to respective product registrations in the USA. As regulatory requirements changed over time - for the purpose of our analyses presented in this study - we chose to map the so-called intermediate IGA categories of the older 7-point scale into the respective categories of the currently preferred 5-point scale.

We defined successful therapeutic intervention by dichotomization of the IGA categories, according to the established regulatory and clinical research conventions: patients with treatment success, i.e., improvement in IGA to "clear" or "minimal" were called "responders," and those with treatment failure, i.e., staying in the range of IGA "mild" to "severe" were called "nonresponders" (Table 2). The responder criterion for the second relevant parameter of disease severity, the number of lesions, was to be defined.

\section{Statistical analysis}

All patients from the full analysis sets of the studies were included in the analyses according to the intention-to-treat principle. All the available data were taken into account, i.e., multiple determinations of the number of lesions and IGA scores for each patient were analyzed. Missing values were not imputed. All variables were analyzed by descriptive statistics including mean, standard deviation, median, and interquartile range. Absolute and relative frequencies were calculated for count data, and mean and standard deviation were calculated for continuous data. Boxplots were drawn, using 1.5 times the interquartile range as the maximal length of the whiskers. Outlying observations were not shown.

The relationship of the IGA and the number of lesions was analyzed using the Jonckheere-Terpstra test ${ }^{13}$ for an ordered alternative hypothesis.

The optimal cutoff point for the number of lesions between the patients rated as "clear/minimal" (responders) and "mild to severe" (nonresponders) was determined by a nonparametric discriminant analysis using normal kernels, unequal bandwidths and the dichotomized IGA defined earlier as the anchor variable. We also performed a sensitivity analysis between the patients rated as "minimal" (responders) and "mild" (nonresponders) that excluded patients rated as "clear," "moderate," or "severe."

Furthermore, the difference between the highest number of lesions still rated as responder vs the lowest number still not rated as nonresponder was determined on subject level and presented descriptively.

\section{Results}

A total of 2,748 patients were included in the database, providing 12,410 measurements. About $72 \%$ of patients were female, and $95 \%$ of patients were Caucasians (Table 3 ).

The IGA score worsened with increasing number of lesions: for IGA score "clear," a mean number of $0.2 \pm 0.75$ lesions (median 0 lesions [0-0]) were found, and for IGA score "severe", 28.4 \pm 14.66 lesions (median 26 lesions [18-36]; $p<0.0001$; Table 4).

Table 5 summarizes the correlation between the improvement in IGA score and the reduction in lesions. The more improvement in the IGA score the more pronounced was the lesion reduction: an improvement of 1 in IGA score resulted in a reduction of $12.9 \pm 8.0$ lesions (median -11 lesions $[-16$

Table 2 Numerical score and definitions of rosacea severity and definition of "responders" and "nonresponders"

\begin{tabular}{|c|c|c|c|}
\hline $\begin{array}{l}\text { Numerical } \\
\text { score }\end{array}$ & Definition & Description & $\begin{array}{l}\text { Responder } \\
\text { definition }\end{array}$ \\
\hline 0 & Clear & No papules and/or pustules; no or residual erythema; no or mild to moderate telangiectasia & Clear/minimal $=$ \\
\hline I & Minimal & Rare papules and/or pustules; residual to mild erythema; mild to moderate telangiectasia & $\begin{array}{l}\text { treatment success: } \\
\text { responder }\end{array}$ \\
\hline 2 & Mild & Few papules and/or pustules; mild erythema; mild to moderate telangiectasia & Mild to severe $=$ \\
\hline a,b & $\begin{array}{l}\text { Mild to } \\
\text { moderate }\end{array}$ & $\begin{array}{l}\text { Distinct number of papules and/or pustules; mild to moderate erythema; mild to moderate } \\
\text { telangiectasia }\end{array}$ & $\begin{array}{l}\text { treatment failure: } \\
\text { nonresponder }\end{array}$ \\
\hline 3 & Moderate & Pronounced number of papules and/or pustules; moderate erythema; mild to moderate telangiectasia & \\
\hline $\mathrm{a}, \mathrm{c}$ & $\begin{array}{l}\text { Moderate to } \\
\text { severe }\end{array}$ & $\begin{array}{l}\text { Many papules and/or pustules, occasionally with large inflamed lesions; moderate erythema; } \\
\text { moderate degree of telangiectasia }\end{array}$ & \\
\hline 4 & Severe & $\begin{array}{l}\text { Numerous papules and/or pustules, occasionally with confluent areas of inflamed lesions; moderate } \\
\text { or severe erythema; moderate or severe telangiectasia }\end{array}$ & \\
\hline
\end{tabular}

Notes: aHistorical intermediate score, used in older studies. ' For our analyses, this category has been mapped to IGA category 3 "moderate." 'For our analyses, this category has been mapped to IGA category 4 "severe."

Abbreviation: IGA, Investigator Global Assessment. 
Table 3 Subject demographics at baseline $(n=2,748)$

\begin{tabular}{ll}
\hline Variable & $\mathbf{N}(\%)$ \\
\hline Gender & \\
$\quad$ Female & $1,982(72.1)$ \\
Male & $766(27.9)$ \\
Age group (years; mean \pm SD) & $49.3 \pm 12.5$ \\
BMI (kg/m² mean \pm SD) & $29.7 \pm 7.0$ \\
Ethnic group & \\
Caucasian & $2,599(94.6)$ \\
Hispanic & $56(2.0)$ \\
Black & $28(1.0)$ \\
Asian & $25(0.9)$ \\
Others & $23(0.8)$ \\
Not reported & $17(0.6)$ \\
\hline
\end{tabular}

Abbreviation: BMI, body mass index.

Table 4 Lesion count by IGA 5-point scale

\begin{tabular}{llllll}
\hline IGA score & $\mathbf{N}^{\mathbf{a}}$ & Mean & SD & Median & IQR \\
\hline Clear & 536 & 0.20 & 0.75 & 0 & {$[0$ to 0$]$} \\
Minimal & 1,924 & $2.8 \mathrm{I}$ & 2.50 & 2 & {$[\mathrm{I}$ to 4$]$} \\
Mild & 3,012 & 6.73 & 4.50 & 6 & {$[4$ to 9$]$} \\
Moderate & 6,078 & 15.14 & 8.94 & 14 & {$[9$ to 19$]$} \\
Severe & 860 & 28.40 & 14.66 & 26 & {$[18$ to 36$]$} \\
\hline
\end{tabular}

Note: ${ }^{\text {aAll }}$ observations (multiple observations per subject possible).

Abbreviations: IGA, Investigator Global Assessment; IQR, interquartile range.

Table 5 Lesion count change from baseline by IGA change from baseline

\begin{tabular}{llllll}
\hline $\begin{array}{l}\text { Change in IGA } \\
\text { score }\end{array}$ & $\mathbf{N}^{\mathrm{a}}$ & Mean & SD & Median & IQR \\
\hline Improved by 4 scores & 92 & -21.20 & 9.21 & -19 & {$[-25.5$ to -14.0$]$} \\
Improved by 3 scores & 619 & -18.01 & 9.23 & -15 & {$[-20.0$ to -12.0$]$} \\
Improved by 2 scores & 1,904 & -15.79 & 8.00 & -14 & {$[-19.0$ to -10.0$]$} \\
Improved by I score & 3,231 & -12.92 & 8.03 & -11 & {$[-16.0$ to -8.0$]$} \\
Unchanged & 3,621 & -6.37 & 8.95 & -6 & {$[-11.0$ to -1.0$]$} \\
Worsened by I score & 195 & 3.41 & 13.90 & I & {$[-5.0$ to +7.0$]$} \\
\hline
\end{tabular}

Note: ${ }^{2} A l l$ observations (multiple observations per subject possible).

Abbreviations: IGA, Investigator Global Assessment; IQR, interquartile range. to -0]), and an improvement of 4 in IGA score resulted in a reduction of 21.2 \pm 9.2 lesions (median -19 lesions [ -25.5 to $-14]$; $p<0.0001)$. An unchanged IGA score as assessed by the investigators showed a reduction of $6.37 \pm 8.95$ lesions (median -6 lesions [ -11 to -1$]$ ).

Applying the IGA dichotomization into responders (clear/ minimal) and nonresponders (mild to severe; Table 2), a clear difference in the mean number of lesions was seen: responders showed 2.23 \pm 2.48 lesions (median 2 lesions [0-3]), and nonresponders showed 13.74 \pm 10.40 lesions (median 12 lesions [6-18]). The optimal cutoff point between responders and nonresponders was a mean of 5.69 lesions as determined by statistical discriminant analysis (Figure 1). The sensitivity analysis based on $39.8 \%$ of the available observation yielded a cutoff between minimal and mild of 4.40 (Figure 2).

A total of 1,206 patients had at least 1 measurement where the IGA score was "clear"/"minimal" and at least 1 measurement where the IGA score was "mild" to "severe," thus permitting an intra-individual comparison. The mean of the individuals' maximal number of lesions rated as "clear"/"minimal" was $3.17 \pm 2.79$ (median 3 lesions [1-4]), and the mean of the individuals' minimal lesion count rated as

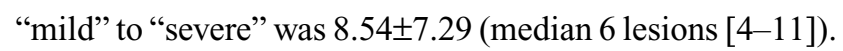

\section{Discussion}

The goal of our study was to empirically generate a responder definition based on the number of facial rosacea lesions. While the IGA score of "clear/minimal" defined a responder and an IGA score of "mild to severe" defined a nonresponder, the corresponding numbers of lesions were still unknown.

We reviewed 29 publications dating from 1971 to 2015 and a Cochrane report involving 2 or more active pharmaceutical treatments for rosacea. ${ }^{5}$ In the majority of publications, comparisons of treatment effects were based on $p$-values obtained from different statistical testing methods,

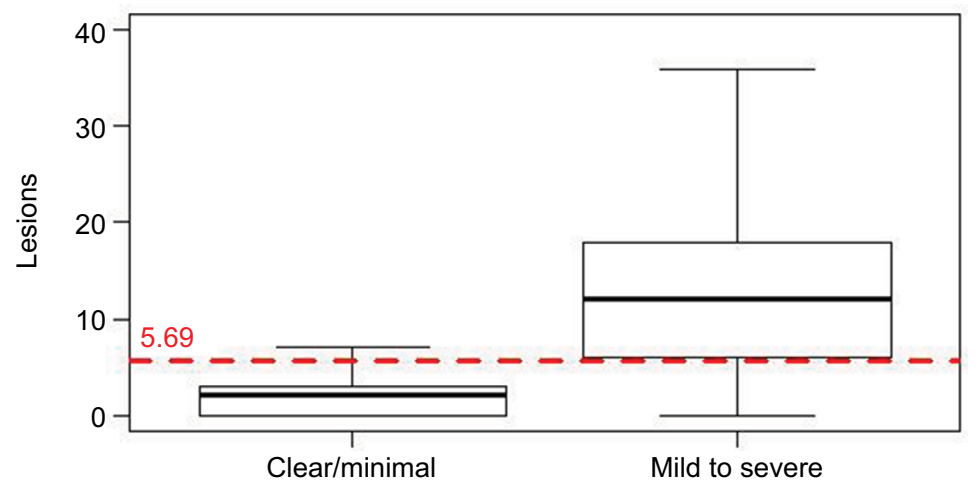

Figure I Boxplot of the number of rosacea lesions by IGA score of "clear"/"minimal" (responders) vs "mild" to "severe" (nonresponders). Note: The dashed horizontal line refers to the optimal separation threshold as determined by statistical discriminant analysis.

Abbreviation: IGA, Investigator Global Assessment. 


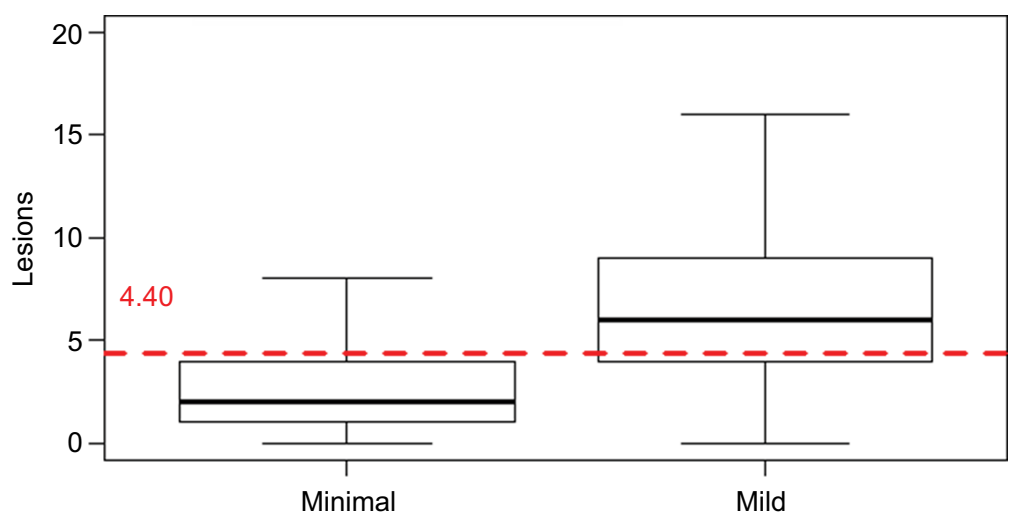

Figure 2 Boxplot of the number of rosacea lesions by IGA score of "minimal" vs "mild."

Note: The dashed horizontal line refers to the optimal separation threshold as determined by statistical discriminant analysis. Abbreviation: IGA, Investigator Global Assessment.

but without disclosing a definition of treatment success or what should be regarded as a responder or nonresponder. Only 2 publications reported a priori assumptions of what would be regarded as "clinically significant difference." Maddin ${ }^{14}$ defined a "minimal clinically important difference" as a difference of 5 lesions between 2 interventions, while Taieb et $\mathrm{al}^{15}$ powered their study to detect a $10 \%$ difference in the number of lesions between 2 interventions. Wolf et $\mathrm{al}^{16}$ defined a non-inferiority margin a priori as a difference not exceeding $15 \%$ in lesion count reduction between the 2 treatments. None of the authors provided a clinical rationale for these differences. Finally, also 2 large meta-analyses comparing treatments for rosacea did not define a minimal clinically important difference, nor did they provide a noninferiority margin. ${ }^{5,17}$ To the best of our knowledge, this is the first publication presenting an empirically generated definition of treatment success.

Based on the number of lesions, we found responders to show a median of 2 lesions ([0-3]), and nonresponders a median of 12 lesions ([6-18]). The optimal cutoff point between both groups was between 5 and 6 lesions (5.69 lesions). This cutoff was confirmed by a sensitivity analysis using only "minimal" and "mild" assessments (39.8\% of the total database) that gave a cutoff of 4.40 lesions.

Thus, differences in lesion counts between different treatment groups can be assessed, and patients with treatment success and failure could be easily and unambiguously categorized. In addition, the subgroup of patients providing the possibility of intra-individual comparisons confirmed the overall results.

Our findings might be helpful for documenting treatment outcome for the day-to-day routine in dermatological practice. Furthermore, our responder definition might be useful in clinical studies investigating innovative treatment options for papulopustular rosacea. In clinical Phase II and III studies, an improved a priori definition of successful therapeutic intervention facilitates the interpretation of the results. In addition, given that the lesion count is an objective disease severity measure that is easily standardized across different studies, the availability of a responder definition based on lesion count provides interpretational independence from the different IGA systems. This may improve the setup of future clinical studies in this area.

We acknowledge 2 limitations in our study: first, the vast majority of data were on 1 compound (azelaic acid) and only a few patients were treated with active comparators (e.g., metronidazole and doxycycline). However, since our analysis considered clinically assessed response irrespective of the intervention, we consider the possible impact as low. Second, our study could not evaluate interrater reliability of lesion count. Although lesion count is a well-established method in clinical trials and medical practice, this could be an interesting question for future research to address.

\section{Conclusion}

The calculated cutoff point of 5.69 lesions allows discrimination of responders ( 5 or less remaining lesions) and nonresponders (6 or more remaining lesions) of therapeutic interventions in rosacea. As this is the first publication providing a responder definition based on the number of lesions, we suggest utilizing both end points - IGA and number of lesions - in clinical research programs for the near future.

\section{Acknowledgment}

We thank all patients and investigators who participated in the clinical study program. Bayer AG funded the journal's publication fees.

\section{Disclosure}

All the authors are full-time employees of Bayer AG. The authors report no other conflicts of interest in this work. 


\section{References}

1. Wilkin J, Dahl M, Detmar M, et al. Standard classification of rosacea: report of the National Rosacea Society Expert Committee on the classification and staging of rosacea. J Am Acad Dermatol. 2002;46(4):584-587.

2. Bohm D, Schwanitz P, Stock Gissendanner S, Schmid-Ott G, Schulz W. Symptom severity and psychological sequelae in rosacea: results of a survey. Psychol Health Med. 2014;19(5):586-591.

3. Steinhoff M, Schauber J, Leyden JJ. New insights into rosacea pathophysiology: a review of recent findings. J Am Acad Dermatol. 2013;69(6 suppl 1):S15-S26.

4. Tan J, Berg M. Rosacea: current state of epidemiology. J Am Acad Dermatol. 2013;69(6 suppl 1):S27-S35.

5. van Zuuren EJ, Fedorowicz Z, Carter B, van der Linden MMD, Charland L. Interventions for rosacea. Cochrane Database Syst Rev. 2015;4:CD003262.

6. Thiboutot D, Thieroff-Ekerdt R, Graupe K. Efficacy and safety of azelaic acid $(15 \%)$ gel as a new treatment for papulopustular rosacea: results from two vehicle-controlled, randomized phase III studies. $J$ Am Acad Dermatol. 2003;48(6):836-845.

7. Elewski BE, Fleischer AB Jr, Pariser DM. A comparison of $15 \%$ azelaic acid gel and $0.75 \%$ metronidazole gel in the topical treatment of papulopustular rosacea: results of a randomized trial. Arch Dermatol. 2003;139(11):1444-1450.

8. Thiboutot DM, Fleischer AB, Del Rosso JQ, Rich P. A multicenter study of topical azelaic acid 15\% gel in combination with oral doxycycline as initial therapy and azelaic acid 15\% gel as maintenance monotherapy. J Drugs Dermatol. 2009;8(7):639-648.
9. Thiboutot DM, Fleischer AB Jr, Del Rosso JQ, Graupe K. Azelaic acid $15 \%$ gel once daily versus twice daily in papulopustular rosacea. J Drugs Dermatol. 2008;7(6):541-546.

10. Draelos ZD, Elewski BE, Harper JC, et al. A phase 3 randomized, double-blind, vehicle-controlled trial of azelaic acid foam $15 \%$ in the treatment of papulopustular rosacea. Cutis. 2015;96(1):54-61.

11. Del Rosso JQ, Bruce S, Jarratt M, Menter A, Staedtler G. Efficacy of topical azelaic acid (AzA) gel 15\% plus oral doxycycline $40 \mathrm{mg}$ versus metronidazole gel $1 \%$ plus oral doxycycline $40 \mathrm{mg}$ in mild-to-moderate papulopustular rosacea. J Drugs Dermatol. 2010;9(6):607-613.

12. Draelos ZD, Elewski B, Staedtler G, Havlickova B. Azelaic acid foam $15 \%$ in the treatment of papulopustular rosacea: a randomized, doubleblind, vehicle-controlled study. Cutis. 2013;92(6):306-317.

13. Jonckheere AR. A distribution-free k-sample test against ordered alternatives. Biometrika. 1954;41:133-145.

14. Maddin S. A comparison of topical azelaic acid $20 \%$ cream and topical metronidazole $0.75 \%$ cream in the treatment of patients with papulopustular rosacea. J Am Acad Dermatol. 1999;40(6 pt 1):961-965.

15. Taieb A, Ortonne JP, Ruzicka T, et al. Superiority of ivermectin $1 \%$ cream over metronidazole $0.75 \%$ cream in treating inflammatory lesions of rosacea: a randomized, investigator-blinded trial. $\mathrm{Br} J$ Dermatol. 2015;172(4):1103-1110.

16. Wolf JE Jr, Kerrouche N, Arsonnaud S. Efficacy and safety of once-daily metronidazole $1 \%$ gel compared with twice-daily azelaic acid $15 \%$ gel in the treatment of rosacea. Cutis. 2006;77(4 suppl):3-11.

17. Yoo J, Reid DC, Kimball AB. Metronidazole in the treatment of rosacea: do formulation, dosing, and concentration matter? J Drugs Dermatol. 2006;5(4):317-319.
Clinical, Cosmetic and Investigational Dermatology

\section{Publish your work in this journal}

Clinical, Cosmetic and Investigational Dermatology is an international, peer-reviewed, open access, online journal that focuses on the latest clinical and experimental research in all aspects of skin disease and cosmetic interventions. This journal is included on PubMed. The manuscript management system is completely online

\section{Dovepress}

and includes a very quick and fair peer-review system, which is all easy to use. Visit http://www.dovepress.com/testimonials.php to read rea quotes from published authors 